\title{
Tamoxifen Stimulates Melatonin Secretion After Exposure to a Mammary Carcinogen, the Dimethyl Benz(a)Anthracene, in Sprague Dawley Female Rat
}

\author{
Marianne Beau Yon De Jonage-Canonico ${ }^{1}$, Véronique Lenoir ${ }^{1}$, Berthe Vivien-Roels ${ }^{2}$, Paul Pevet ${ }^{2}$, \\ Robert Scholler ${ }^{1}$ and Bernard Kerdelhue*,1
}

\author{
${ }^{1}$ Laboratoire de Neuroendocrinologie, INSERM U 648, UFR Biomédicale des Saints-Pères, PARIS 5, 45 Rue des Saints \\ Pères, 75270 - PARIS CEDEX 06, France \\ ${ }^{2}$ Institut des Neurosciences Cellulaires et Intégratives, UMR 7168/LC2 ULP CNRS, département de Neurobiologie des \\ Rythmes, 5 Rue Blaise Pascal , 67000- STRASBOURG, France
}

\begin{abstract}
A single intragastric administration of 7,12-dimethylbenz(a)anthracene (DMBA) has been shown to induce mammary tumors in young cycling female Sprague-Dawley rats. The appearance of the tumors is preceded, during the latency phase, by a series of neuroendocrine disturbances, including attenuation of the preovulatory Luteinizing Hormone surge and Gonadotropin-Releasing Hormone release and amplification of the preovulatory $17 \beta$-Estradiol (E2) surge. Also, E2 treatment leads to a complete blunting of the Isoproterenol-induced stimulation of Melatonin secretion.In this study, we examined the hypothesis that Tamoxifen, an antagonist of E2, would stimulate the Isoproterenol-induced Melatonin (MT) secretion from the pineal gland, during the latency phase.

Sprague-Dawley rats, 55-60 days of age, received, on the Estrous day of the Estrous cycle, a single dose of $15 \mathrm{mg}$ DMBA delivered by intragastric intubation. In order to avoid possible interactions with endogenous steroids or mammary tumorderived compounds, they were ovariectomized 5 days later and, one month later, sacrificed by decapitation at $10 \mathrm{a} . \mathrm{m}$. Then, pineal glands were removed and placed in perifusion chambers containing Hanks 199 medium. The medium was satured with $\mathrm{O}_{2} / \mathrm{CO}_{2}(95 \% / 5 \%)$ and its $\mathrm{pH}$ was 7.4. Ten independent chambers were immersed in a water bath at $37^{\circ} \mathrm{C}$. Each pineal gland received medium (flow rate $: 0.16 \mathrm{ml} / \mathrm{min}$ ) through a system of input lines. The fractions were collected every $10 \mathrm{~min}$, and immediately frozen at $-20^{\circ} \mathrm{C}$ until Melatonin RIA. Experiments were repeated to obtain up to five experimental points for each treatment. Tamoxifen $\left(10^{-9}\right.$ to $\left.10^{-7} \mathrm{M}\right)$ was applied during the entire perifusion period (7 hours). Isoproterenol $\left(10^{-6} \mathrm{M}\right)$ was applied for 20 min after 3 hours in perifusion. Melatonin concentrations and Areas Under the Curves were compared using two-factor ANOVA as well as parametric or nonparametric two-sample methods after testing sample normality.

In vehicle treated rats, Tamoxifen treatment, at the concentration of $10^{-9} \mathrm{M}$, leads to a non significant amplification of the Isoproterenol-induced stimulation of Melatonin secretion.

In DMBA-treated rats, Tamoxifen treatment leads,starting from $10^{-9} \mathrm{M}$ to a dose- dependent increase (up to $400 \%$ increase) of the Isoproterenol-induced stimulation of Melatonin .

The results suggest that in addition to the well documented beneficial effects of Tamoxifen at the mammary gland level, this E2 antagonist may also have, after DMBA treatment, an additional beneficial effect at the pineal gland level throughout the stimulation of Melatonin, which exerts an inhibitory action on the induction and on the growth of breast cancers.
\end{abstract}

Keywords: Dimethylbenz(a)anthracene, female rat, mammary cancer, melatonin, tamoxifen.

\section{INTRODUCTION}

Female Sprague-Dawley rats develop mammary adenocarcinoma in response to a single intragastric dose $(15 \mathrm{mg})$ of the carcinogen 7,12-dimethylbenz(a)anthracene (DMBA) [1]. The mechanisms by which DMBA induces mammary tumors in rats are well characterised. This carcinogen interacts with rapidly proliferating cells in the terminal end buds, forming DNA adducts, which in turn participate in transforming the normal terminal end bud cells to malignant

*Address correspondence to this author at the Laboratoire de Neuroendocrinologie, INSERM U 648, UFR Biomedicale des Saints Pères, 45, Rue des Saints Pères, 75270-PARIS CEDEX 06, France; Tel: + 331 42864094; Fax: + 331 42864070; E-mail: bernard.kerdelhue@biomedicale.univ-paris5.fr pathways [2-4]. The susceptibility of Sprague-Dawley rats to DMBA is maximal at 55-60 days of age and is abolished by ovariectomy, suggesting that the inducible action of the carcinogen depends on ovarian hormones [5].

Furthermore, the appearance of DMBA-induced adenocarcinoma is preceded by a series of disturbances of the Hypothalamo-Pituitary-Gonadal during the latency period. Estrous cycles are associated with blunted preovulatory surges of LH and FSH [6], increased surges of plasma 17 $\beta$-Estradiol [7] and disruption in Hypothalamic Gonadotropin-Releasing Hormone $(\mathrm{GnRH})$ and its Pituitary Receptor Gene Expression patterns [8]. Moreover, ovariectomized rats pre-treated 5 days before ovariectomy with DMBA, exhibit one month later, a blunted LH release in response to in vivo Estradiol 
replacement and a reduced GnRH release as measured in vitro using synaptosomes from the mediobasal hypothalamus [9], suggesting a possible direct and long lasting action of DMBA at the brain level. Also, a long-term deregulation of the circadian and $17 \beta$-Estradiol-induced LH, prolactin and corticosterone secretion was seen after DMBA administration[10]. Last but not least, Estradiol treatment leads, in a dose dependant manner, to a complete blunting of the spontaneous and Isoproterenol-induced Melatonin secretion from the in vitro perifused pineal gland during the latency period [11].

On the other hand, it has been shown that Melatonin which is involved in the control of reproduction $[12,13]$ also exerts, in vivo [14-15] and in vitro [16-17], an oncostatic activity on the mammary tissue in activating the Estrogen Receptor (ER) for DNA binding [18], or in modulating the ER mRNA expression [19] or the increase of the ER binding activity [20]. Surprisingly, Melatonin has also a strong preventive effect on the mammary carcinogenesis induced by DMBA [21].

In view of the well documented antiestrogenic properties of Tamoxifen [22], we therefore examined the long-term effects of Tamoxifen on Melatonin secretion induced by Isoproterenol from the pineal gland of animals which were treated, one month before, by a single administration of DMBA.

\section{MATERIALS AND METHODS}

\section{Animals}

The animal studies described in this manuscript were conducted in accord with accepted standards of human care. The study was approved by the authors' institutional committee on animal care.

Seventy Dawley female rats (Charles River), 49 to 51 days of age, were used in the present study.
They were housed (6-7 animals per cage), under controlled temperature $\left(21 \pm 1^{\circ} \mathrm{C}\right)$. The animal housing room diurnal cycle was 12 hours light/12 hours darkness (light on: from 7 a.m. to 7 p.m.). The animals receive UAR food and water ad libidum.

After 4 or 5 days of acclimatation, the rats received 15 $\mathrm{mg}$ of DMBA in $1 \mathrm{ml}$ of sesame oil or $1 \mathrm{ml}$ of the vehicle alone, on the day of Estrous of the Estrous cycle. All rats were treated at 55 days of life, since the induction of the mammary cancer is maximal at this time of life [1]. Five days after this treatment, the rats were anesthetized with 70 mg chloral hydrate in $1 \mathrm{ml}$ of saline solution and ovariectomized. Then, they were sacrificed by decapitation one month later, and the pineal gland was removed and perfused by using previously described perfusion methods $[11,23]$

Briefly, the pineal glands were collected in $1 \mathrm{ml}$ of Medium 199 (Sigma-Aldrich), without phenol red, which contains HANK medium with $\mathrm{NaHCO}_{3}(0.35 \mathrm{~g} / \mathrm{l})$, BSA $(1 \mathrm{~g} / \mathrm{l})$ and Bacitracine $(0.14 \mathrm{~g} / 1), \mathrm{pH}$ 7.4. It was equilibrated with a mixture of $95 \% \mathrm{O}_{2} / 5 \% \mathrm{CO}_{2}$. They were perfused in the same medium at a flow rate of $0.2 \mathrm{ml} / \mathrm{min}$. One pineal gland was used per perfused chamber.

Each series of perfusion was performed during 7 hours; 10 minutes fractions were collected. The perfusion apparatus allowed to perifuse 20 pineal glands simultaneously. Experiments were repeated to obtain 5 experimental points for each treatment.

A 170-min pre-incubation period was required to reach a stable level of the concentration of Melatonin. After this period, the pineal glands were stimulated with $10^{-6} \mathrm{M}$ Isoproterenol (Sigma), a $\beta$-adrenergic receptor agonist, for $20 \mathrm{~min}$ utes between fraction number 17 and 18. This concentration of Isoproterenol provokes an almost maximal release of Melatonin.

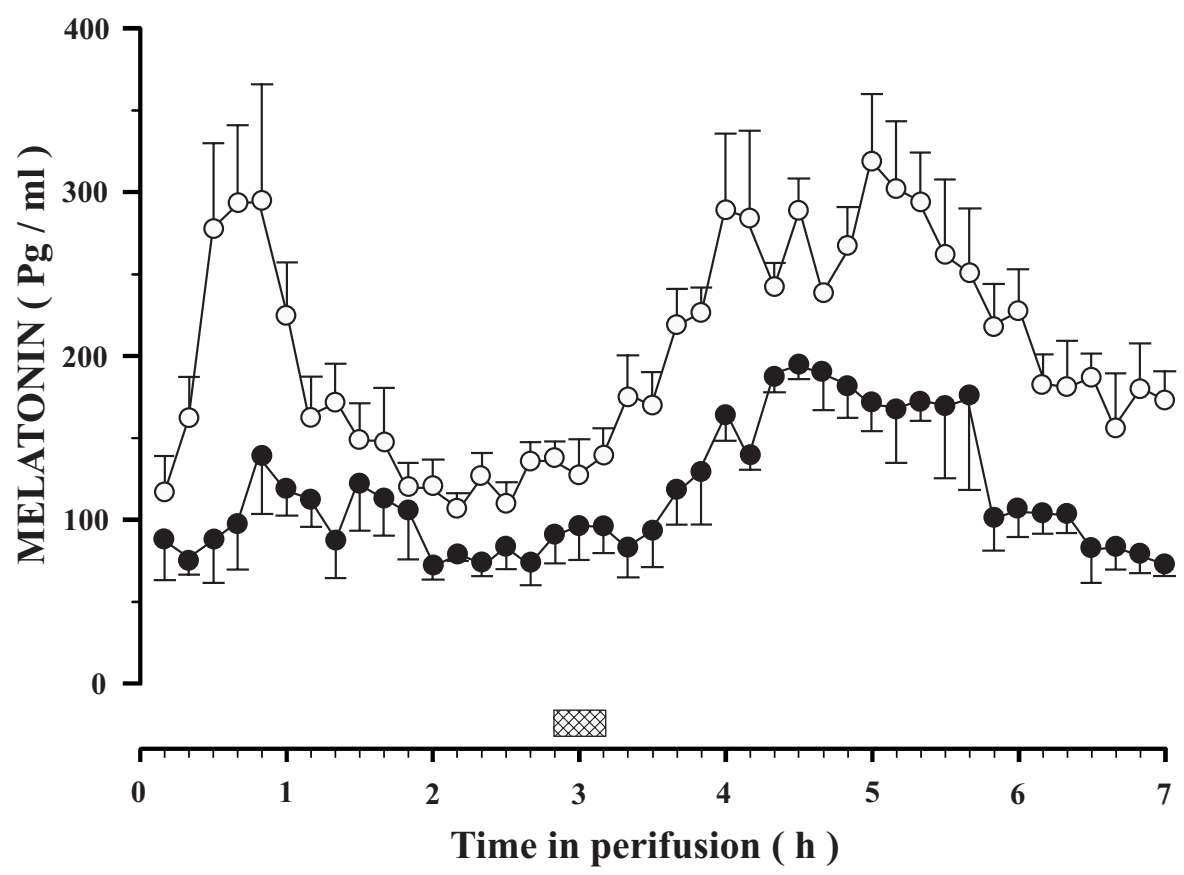

Fig. (1). Medium concentration of Melatonin ( $\mathrm{pg} / \mathrm{ml} \pm \mathrm{SEM})$ from perifused pineal gland $(\mathrm{n}=5)$ of vehicule-treated ( $-\mathrm{O}-)$ or DMBAtreated (—- ) and ovariectomized rat. Isoproterenol $\left(10^{-6} \mathrm{M}\right)$ was added for 20 min during the indicated period ( 

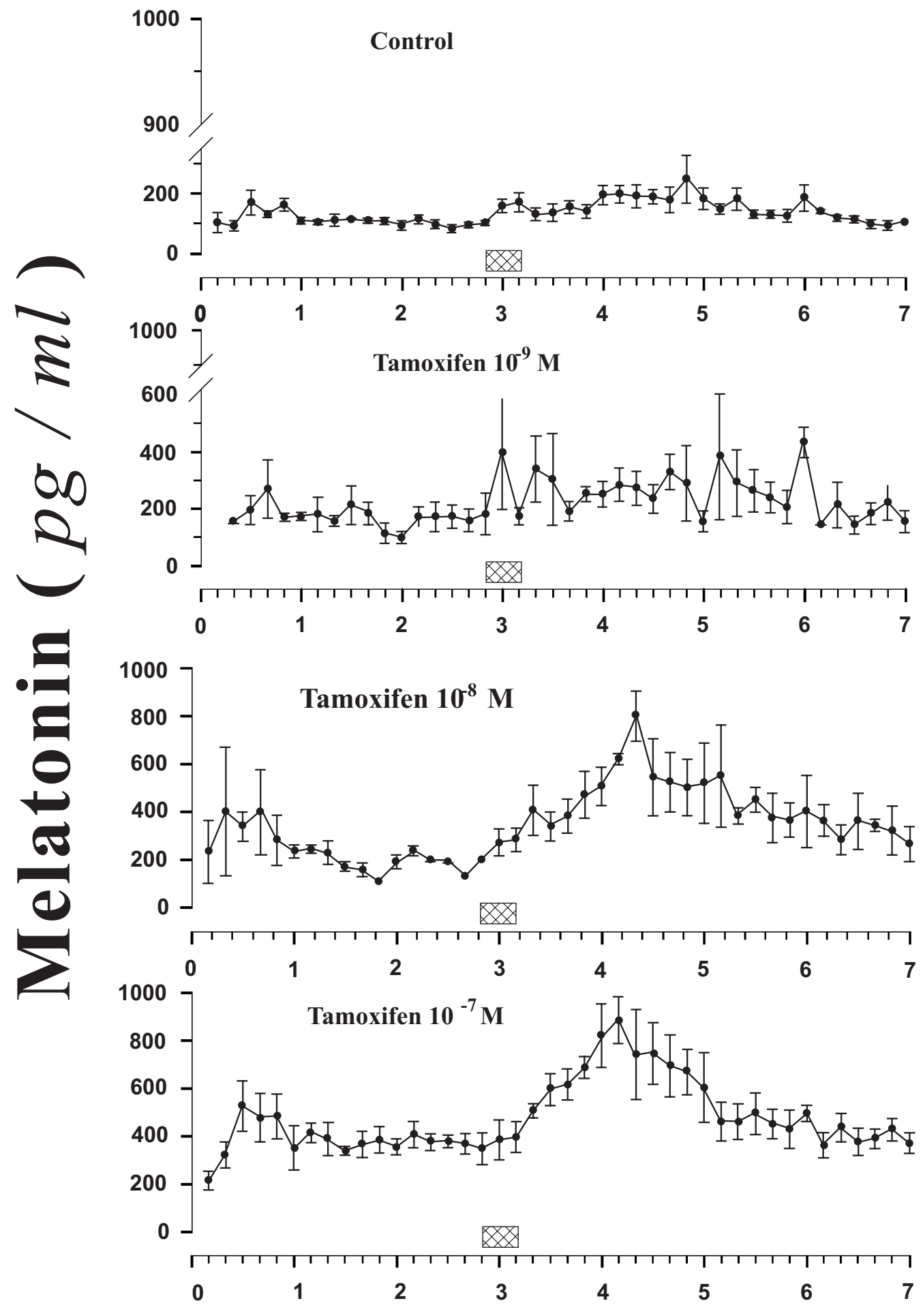

Time in perifusion $(\mathrm{h})$

Fig. (2). Medium concentration of Melatonin(pg/ml \pm SEM) from perifused pineal gland $(\mathrm{n}=5)$ of DMBA-treated and ovariectomized rat in presence of various concentrations of Tamoxifen applied during the entire perifusion period.Isoproterenol( $\left(10^{-6} \mathrm{M}\right)$ was added for 20 min during the indicated period (

\section{Measurement of Medium Melatonin}

The determination of Melatonin concentration was made by a previously validated RIA method, without extraction of the samples [24].

Briefly, the Rabbit Polyclonal Melatonin Antiserum (AB 19540) was kindly given to us by Doctor RAVAULT
(INRA, Nouzilly, France). It was used at a final dilution of $1 / 100000$, in a total volume of $500 \mu 1$.

The $\mathrm{I}^{125}$ Melatonin was from NEN (Life Science Products Inc. Boston, MA). Melatonin used as standard was from Sigma. 
The antibody/Antigen complex was isolated by using a pony antiserum against Rabbit $\gamma$-Globulins.

The limit of sensitivity of the assay,defined as two standard deviations of melatonin binding was $1 \mathrm{pg} / \mathrm{tube}$. The minimum detection level for the assay was between 1 and 2 $\mathrm{pg} /$ tube. The intra- and inter-assay coefficients of variation were less than $4 \%$ and $6 \%$, respectively.

\section{Statistical Analysis}

The normality of data was analysed by the KolmogorovSmirnov and Shapiro Wilk tests. The influence of perifusion time and treatment on Melatonin concentrations and Areas Under the Curves were analysed with two factor ANOVA followed by two-sample comparisons.

In the case of samples drawn from gaussian populations, the Student's t or the Welsh tests was used.

A $p$ value $<0.05$ was considered significant.

\section{RESULTS}

\section{Effect of DMBA Treatment on the In vitro Release Of Melatonin (Fig. 1)}

In absence of DMBA treatment, a marked biphasic pattern of Melatonin secretion was observed. Before the application of Isoproterenol, a spontaneous secretion of Melatonin, with maximal values by 40-50 min after the beginning of the perifusion, was observed. At that time, a 3 fold increase in the concentration of melatonin was observed. After the application of isoproterenol, maximal values were seen by $60-120 \mathrm{~min}$ after the beginning of the application. Again, a 3 fold increase in the concentration of melatonin was observed.

In presence of DMBA treatment, a marked modification of the patterns of the secretion of Melatonin was observed. Overall, the pattern was similar to the pattern observed in absence of DMBA treatment but mean values were almost two times lower than those observed in controls. Before the application of Isoproterenol, the spontaneous secretion of Melatonin was almost completely abolished. A non significant $50 \%$ increase was noted. After the application of Isoproterenol, the pattern of secretion of Melatonin follows the pattern observed in controls but mean values were again lower than those seen in controls.

The Area Under the Curve (AUC), expressed as pg/ml.mins ( Mean + SEM), was $83216 \pm 4350$ in absence of DMBA treatment vs $47020 \pm 4389$ in presence of DMBA treatment; the mean values of the DMBA treated group are very significantly lower than those from the vehicle treated group $(p=0.0007)$

\section{Effect of Increasing Concentrations of Tamoxifen Upon the Spontaneous and the Isoproterenol -Induced Melatonin Secretion (Fig. 2)}

Fig. (2) shows the in vitro effect of increasing concentration of Tamoxifen upon the spontaneous and the Isoproterenol-induced Melatonin secretion from the pineal gland of DMBA-treated rates.

It can be seen, that starting from the concentration of $10^{-9}$ $\mathrm{M}$ a significant increase in the secretion of Melatonin induced by Isoproterenol was observed. However, the spontaneous secretion was not affected. Clearly, a marked effect was seen at the concentration of $10^{-7} \mathrm{M}$ on both the spontaneous and the Isoproterenol-induced Melatonin secretion. A maximal effect on both parameters was observed at the concentration of $10^{-7} \mathrm{M}$.

The Area Under the Curve are given in Table 1. Again, a dose -dependent increase in the total amount of Melatonin secreted was observed.

However, a concentration of $10^{-9} \mathrm{M}$ of Tamoxifen was inefficient in stimulating the secretion of Melatonin from the pineal gland of non DMBA-treated rats.

\section{DISCUSSION}

The results of this study demonstrate that a single intragastric administration of DMBA to Sprague-Dawley female rat induces a long term marked stimulation by Tamoxifen of the spontaneous and Isoproterenol-induced Melatonin secretion from the pineal gland. On the contrary, we previously documented that Estradiol has an opposite effect on Melatonin secretion after DMBA exposure (M.Beau Yon De Jonage-Canonico et al., Reference [11]). The results of this study are summarized in Fig. (3) and Table 2. It can be seen that a complete blunting of the spontaneous and Isoproterenol-induced secretion of Melatonin was observed when Estradiol was applied at the concentration of $10^{-9} \mathrm{M}$. A strong inhibitory effect was already observed at $10^{-10} \mathrm{M}$ of Estradiol.

However, a $10^{-9} \mathrm{M}$ concentration of Estradiol was of a non significant effect on Melatonin secretion.

The influence of ovarian steroids on Melatonin secretion was investigated by several laboratories with conflicting results [25-29]. Interestingly enough, pineal melatonin syn-

Table 1. Statistics of the AUC of medium Melatonin Concentrations from the pineal Gland of DMBA treated and ovariectomized Rat, perifused for 7 hours with increased Concentrations of Tamoxifen and with Isoproterenol (10-6M) for 20 min. ( mean, sem and significance level p).

\begin{tabular}{|c|c|c|c|c|c|}
\hline Treatment & $\begin{array}{c}\text { Mean } \pm \text { SEM } \\
(p g / m l, m i n s)\end{array}$ & \multicolumn{4}{|c|}{ Treatment } \\
\hline Tamoxifen $10^{-9} \mathrm{M}$ & $89295 \pm 8882$ & $0.01(\mathrm{t}) *$ & & $0.07(\mathrm{t})$ & $0.02(\mathrm{t}) *$ \\
\hline Tamoxifen $10^{-8} \mathrm{M}$ & $126957 \pm 24144$ & $0.05(\mathrm{~W}) *$ & $0.07(\mathrm{t})$ & & $0.23(\mathrm{t})$ \\
\hline
\end{tabular}

$\mathrm{t}=$ Student $;$ when unequal variances, $\mathrm{W}=$ Welch $; *$ = significant. 

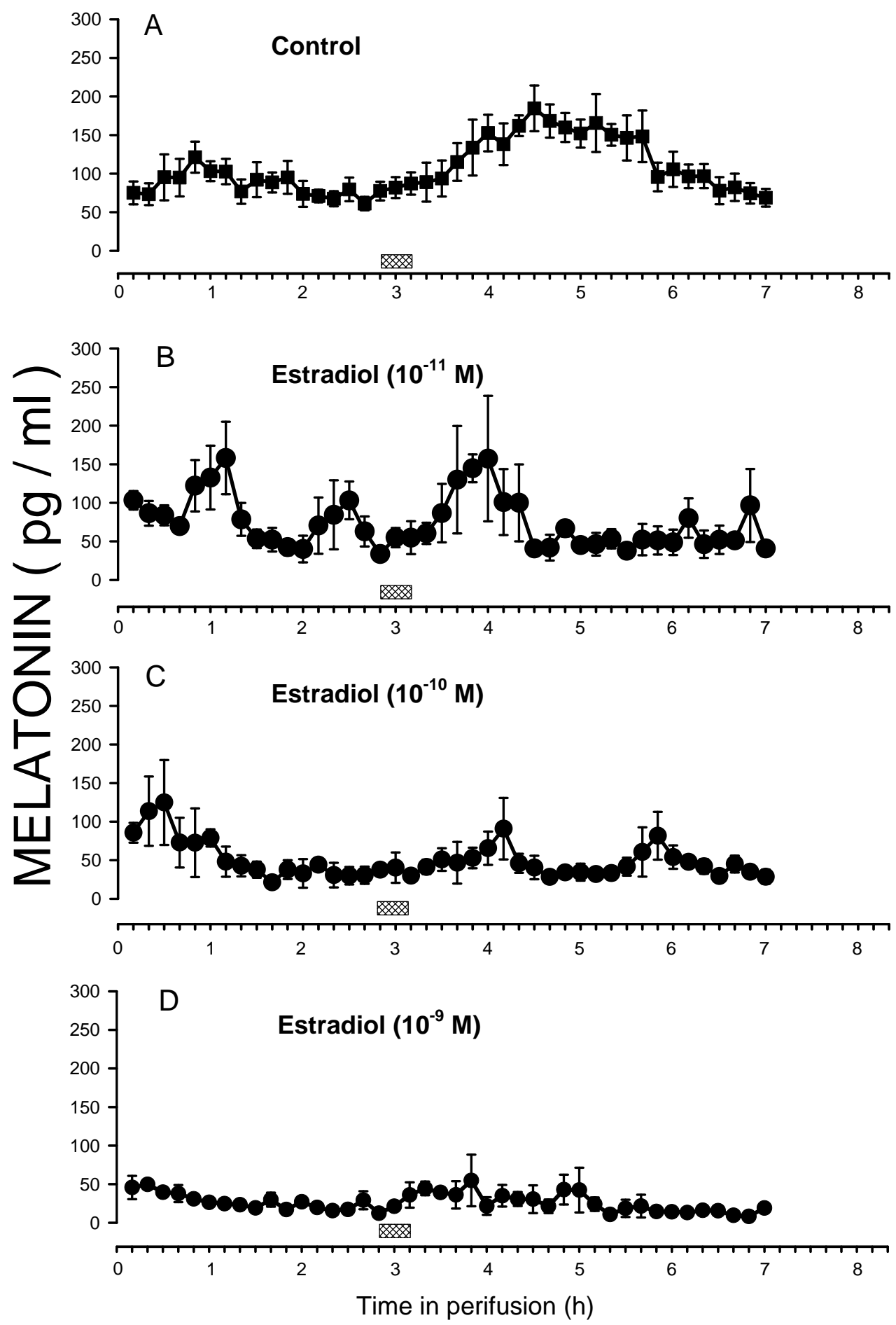

Fig. (3). Medium concentration of Melatonin $(\mathrm{pg} / \mathrm{ml} \pm \mathrm{SEM})$ from perifused pineal gland $(\mathrm{n}=5)$ of DMBA-treated and ovariectomized rat in presence of various concentrations of $\mathrm{E} 2$ applied during the entire perifusion period.Isoproterenol $\left(10^{-6} \mathrm{M}\right)$ was added for 20 min during the indicated Period ( ). From M. Beau Yon De Jonage-Canonico et al. (Ref. [11]).

thesis and release are not altered throughout the estrous cycle in females rats(30) but there are changes in noctural melatonin secretion in perimenopausal women which negatively $\mathrm{h}$ endogenous serum $17 \beta$ Estradiol: there is a transient change in noctural melatonin secretion which be related to the existence of a low estrogen environment(31). The influence of Tamoxifen or others antagonists of ER on Melatonin secretion was, to our knowledge,not documented.
In vivo, Estradiol might also exert an inhibitory influence by inhibiting Norepinephrine release leading to a decrease in Melatonin secretion [29].

Very interestingly, the transient and spontaneous release of Melatonin has been constantly documented. It consisted in a 2 to 3 fold increase in Melatonin secretion which culminates in our experimental conditions on time $45 \mathrm{~min}$, with a return to initial values by $90 \mathrm{~min}$ after the start of the perifu- 
Table 2. Statistics of the AUC of medium Melatonin Concentrations from the pineal gland of DMBA treated and ovariectomized rat, perifused for 7 hours with increasing Concentrations of $\mathrm{E} 2$ and with isoproterenol $\left(10^{-6} \mathrm{M}\right)$ for $20 \mathrm{~min}$.

\begin{tabular}{|c|c|c|c|c|c|}
\hline \multirow{2}{*}{ Treatment } & \multirow{2}{*}{$\begin{array}{c}\text { Mean } \pm \text { SEM } \\
(\boldsymbol{p g} / \text { ml.mins })\end{array}$} & Control & $\mathbf{E 2 ~ 1 0}^{-11} \mathbf{M}$ & E2 10 & \multicolumn{3}{|c|}{ Treatment } \\
\cline { 3 - 5 } & & & $>0.10(\mathrm{t})$ & $<0.008(\mathrm{t}){ }^{*}$ & $<0.005(\mathrm{w})^{*}$ \\
\hline \hline Control & $44018 \pm 6043$ & $>0.10(\mathrm{t})$ & & $>0.08(\mathrm{t})$ & $<0.008(\mathrm{w})^{*}$ \\
\hline $\mathrm{E} 210^{-11} \mathrm{M}$ & $30450 \pm 4255$ & $<0.008(\mathrm{t})^{*}$ & $>0.08(\mathrm{t})$ & & $0.02(\mathrm{t})^{*}$ \\
\hline $\mathrm{E} 210^{-10} \mathrm{M}$ & $20179 \pm 3022$ & $<0.005(\mathrm{w})^{*}$ & $<0.008^{*}$ & $0.02(\mathrm{t})^{*}$ & \\
\hline $\mathrm{E} 210^{-9} \mathrm{M}$ & $10737 \pm 1240$ & & & \\
\hline
\end{tabular}

$\mathrm{t}=$ Student's $t$ test; $\mathrm{w}=$ Welch test,when unequal variances

* statistically significant

From Beau Yon De Jonage-Canonico et al. (Ref. [11]).

sion. It is assumed that this spontaneous release is due to a release of Norepinephrine from surgically sectioned Noradrenergic fibbers from the Superior Cervical Ganglion $[23,25]$ which innervates the pineal gland.

The kinetic characteristics of the Isoproterenol-induced Melatonin secretion have been well documented $[11,23]$. It consisted of a 2-3 fold increase in Melatonin concentration which culminates by $90 \mathrm{~min}$ after the transient addition of Isoproterenol into the perifusion medium. The selected concentration of Isoproterenol $\left(10^{-6} \mathrm{M}\right)$ allows to observe an almost maximal release of Melatonin with a return to prestimulation concentrations by $4 \mathrm{~h}$ after the beginning of the stimulation. In DMBA treated rats, both the spontaneous and the Isoproterenol-induced release of Melatonin were reduced.

The presence of receptors for E2 at the pineal level has been documented [28]. Nevertheless, the presence of ER variants [32] and/or an increase in the affinity of the ER might explain the marked efficiency of E2 to inhibit Melatonin secretion and of Tamoxifen to stimulate Melatonin secretion from the pineal gland. It might result from a modification at the genomic level, either at the transcriptional level, at the epissage of the primary transcript or at the traduction level of the mature messenger.

It is thought that DMBA acts, at the mammary gland level, throughout the formation of metabolites and DNA adduct [33-34] which will provoke the initiation of the mammary carcinogenesis. Also, recent data from our laboratory (data not shown) indicate that DMBA cross the blood brain barrier, reaches at least steroid receptor rich regions of the brain, including the pineal gland, and is able to be locally metabolised. It may be envisioned that DNA adducts could provoke a cascade of morphological and/or biochemical events leading to the long term disruption of the E2 and Tamoxifen control after DMBA treatment.

It has been shown that pinealectomy enhances and Melatonin inhibits tumor growth of DMBA-treated female rat [35-36]. An effect of DMBA on pineal Melatonin biosynthesis, secretion and peripheral metabolism has been documented [37]. Seven days after DMBA treatment of Female Sprague-Dawley rats, nocturnal plasma Melatonin concentrations were depressed by 31-37\% [37]. Also, a depression of nocturnal circulating Melatonin in patients with Primary Breast Cancer has been documented [38-39]. Apparently, this decrease in Melatonin concentration is not due to an increased peripheral metabolism of Melatonin since both nocturnal Melatonin and its main metabolic product 6sulfatoxymelatonin were significantly lowered in patients with Primary Breast Cancer [39]. Therefore, the decrease in nocturnal serum Melatonin concentration is not due to an enhanced degradation to 6-sulfatoxymelatonin in the liver but must be due to reduced activity, for an unknown reason, of the pineal gland [39].Interestingly, it has been shown that the administration of Melatonin markedly reduces the percentage of tumor-bearing animals after administration of DMBA [11]; also, the latency period was increased and the number of tumors per tumor-bearing animal was significantly reduced by a long term melatonin treatment [11].

In view of the present results and of the well documented oncostatic properties of Melatonin, it can be envisioned that the long term stimulation of Melatonin secretion by Tamoxifen may play an additional protective and curative role on breast cancer.Interestingly, it has been documented that the treatment of MCF-7 human breast cancer cells in vitro with Melatonin increases the sensitivity of these cells to Tamoxifen [40].

Taken together, the results show the capacity of tamoxifen to stimulate pineal melatonin synthesis and the importance of pineal ER to modulate melatonin secretion and thus to affect breast cancer evolution.

\section{ACKNOWLEDGEMENTS}

The authors greatly acknowledge the editorial assistance and manuscript preparation of Mrs. Isabelle Michel.

\section{REFERENCES}

[1] Huggins C, Grand LC, Brillantes FP. Mammary cancer induced by a single feeding of polynuclear hydrocarbons and its suppression. Nature 1961; 189: 189-204.

[2] Russo J, Tav IK, Russo IH. Differenciation of the mammary gland and susceptibility to carcinogenesis. Breast Cancer Res Treat 1982; 2: $5-73$.

[3] Russo J, Tait I, Russo IH. Susceptibility of the mammary gland to carcinogenesis III. The cell of origin of rat mammary carcinogens. Am J Pathol 1983; 113: 50-66.

[4] Daniel FB, Jovco NJ. DNA adduct formation by 7,12dimethylbenz[a]anthracene and its noncarcinogenic 2-fluoro analog in the female Sprague-Dawley rats. J Natl Cancer Inst 1983; 70: 111-118.

[5] Dao TL. The role of ovarian hormones in initiating the induction of mammary cancer in rats by polynuclear hydrocarbons. Cancer Res 1962; 22: 975-981. 
[6] Kerdelhué B, El Abed A. Inhibition of preovulatory gonadotropin secretion and stimulation of prolactin secretion by 7,12dimethylbenz[a]anthracene in Sprague-Dawley rats. Cancer Res 1969; 39: 4700-4705.

[7] El Abed A, Kerdelhué B, Castanier M, Scholler R. Stimulation of estradiol-17 $\beta$ secretion by 7,12-dimethylbenz[a]anthracene during mammary tumor induction in Sprague-Dawley rats. J Steroids Biochem 1987; 26: 733-738.

[8] Jakubowski M, Lenoir V, Jimenez-Linan M, et al. Long-Term Effects of the Mammary Carcinogen 7,12Dimethylbenz[a]anthracene on Hypothalamic GonadotropinReleasing Hormone and Its Pituitary Receptor Gene Expression, during the promotion stage, in Female Sprague-Dawley Rats. Breast Cancer Res Treat 2002; 73: 23-29.

[9] Kerdelhué B, Peck EJ. In vitro LHRH release . correlation with the LH surge and alteration by a mammary carcinogen. Peptides 1981; 2: 219-222.

[10] Beau Yon De Jonage-Canonico M, Lenoir V, Scholler R, Kerdelhué B. Long-term dysregulation of circadian and $17 ß$ estradiol induced LH,prolactin and corticosterone secretion after dimethylbenz (a) anthracene administration in the Sprague-Dawley female rat. Breast Cancer Res Treat 2005; 92: 47-50.

[11] Beau Yon De Jonage-Canonico M, Lenoir V, Martin M, Scholler $\mathrm{R}$, Kerdelhué B. Long term inhibition by Estradiol or Progesterone of Melatonin secretion after administration of a mammary carcinogen,the dimethyl benz (a) anthracene, in Sprague-Dawley female rat ; inhibitory effect of Melatonin on mammary carcinogenesis. Breast Cancer Res Treat 2003; 79: 365-377.

[12] Reiter RJ. The pineal gland and its hormones in the control of reproduction in mammals. Endocr Rev 1980; 1: 109-131.

[13] Vanececk J. Inhibitory effect of melatonin on GnRH-induced LH release. Rev Reprod 1999; 4: 67-72.

[14] Blask DE, Hill SM, Orstead KM, Massa JS. Inhibition effects of the pineal hormone Melatonin and underfeeding during the promotional phase of 7, 12 DMBA induced mammary tumorigenesis. J Neural Transm 1986; 67: 125-138.

[15] Blask DE, Sauer L, Dauchy R. Melatonin Inhibition of Cancer Growth in vivo Involves Suppression of Tumor Fatty Acid metabolism via Melatonin Receptor-mediated Signal Transduction Events. Cancer Res 1999 ; 59: 4693-4701.

[16] Cos S, Fernandez R, Güezmes A, Sanchez-Barcelo EJ. Influence of melatonin on invasive and metastatic properties of MCF-7 human breast cancer cells. Cancer Res 1998; 58: 4383-4390.

[17] Martinez-Campa C, Alonso-Gonzalez C, Mediavilla MD, et al. Melatonin inhibits both ER alpha activation and breast cancer cell proliferation induced by a metalloestrogen, cadmium. J Pineal Res 2006; 40: 291-296.

[18] Rato AG, Pedrero JG, Martinez MA, del Rio B, Lazo PS, Ramos S. Melatonin blocks the activation of estrogen receptor for DNA binding. FASEB J 1999; 13: 857-868.

[19] Molis TM, Spriggs LL, Hill SM. Modulation of Estrogen Receptor mRNA Expression by Melatonin in MCF-7 Human Breast Cancer Cells. Mol Endocrinol. 1994; 8: 1681-1690.

[20] Danforth DN, Tamarkin L, Lippman ME. Melatonin increases oestrogen receptor binding activity of human breast cancer cells. Nature 1983; 305: 323-325.

[21] Lenoir V, Beau Yon de Jonage-Canonico M, Perrin M-H, Martin A, Scholler R, Kerdelhué B. Preventive and curative effect of melatonin on mammary carcinogenesis induced by dimethylbenz [a] anthracene in the female Sprague-Dawley rat. Breast Cancer Res 2006; 7: 470-476.

[22] Fischer B, Costantino JP, Wickerham DL, et al. Tamoxifen for prevention of breast cancer : Report of the National Surgical Adjuvant Breast and Bowel project P-1 Study. J Natl Cancer Inst 1998; 90: 1371-1387.

[23] Simmoneaux V, Ouichou A, Pevet P, Masson Pevet M, Vivien Roels, Vaudry H . Kinetic study of melatonin release from rat pin- eal glands using a perifusion technique. J Pineal Res 1989; 7: 6383.

[24] Vivien-Roels B, Pevet P, Masson-Pevet M, Canguilhem B. Seasonal variations in the daily rhythm of pineal gland and/or circulating melatonin and 5-methoxytrytophol concentrations in the European hamster, Cricetus cricetus. Gen Comp Endocrinol 1992; 86: 239-247.

[25] Cardinali DP, Vacas MI, Keller Sarmiento MI, Etchegoyen GS, Pereyra EN, Chuluyan HE. Neuroendocrine integrative mechanism in mammalian pineal gland: effects of steroid and adenohypophysial hormones on melatonin synthesis in vitro. J Steroid Biochem 1987; 27: 565-571.

[26] Ishizuka B, Fusama S, Hirai K, Hosaka T, Hamada N, Amemiya A, Itoh MT. Melatonin secretion from organ-cultured pineal glands of rats : modulation by gonadectomy and gonadotropin-releasing hormone agonist administration. Eur J Endocrinol 2000; 142: 387-392.

[27] Monjir F, Bordon R, Santano C, Abreu P, Hernandez G, Alonso R. Ovarian steroids blocks the isoproterenol-induced elevation of pineal melatonin production in the femele rat. Neurosci Lett 1990; 119: 12-14.

[28] Cardinali DP. Nuclear Receptor Estrogen Complex in the Pineal Gland. Modulation by Sympathetic Nerves. Neuroendocrinology 1977; 24: 333-346.

[29] Alonso R, Abreu P, Fajardo N, et al. Ovarian hormones regulate alpha 1 and beta-adrenoceptor interactions in female rat pinealocytes. Neuroreport 1995; 6: 345-348.

[30] Skorupa AL, Garidou ML, Bothorel B, Saboureau M, Pevet P, Neto JC, Simonneaux V. Pineal melatonin synthesis and release are not altered throughout the estrous cycle in female rats. J Pineal Res 2003; 34: 53-59.

[31] Okatani Y, Morioko N, Wakatsuki A. Changes in nocturnal secretion in perimenopausal women: correlation with endogenous estrogen concentrations. J Pineal Res 2000; 28: 111-118.

[32] Chaidarun SS, Alexander JM. A Tumor-Specific Truncated Estrogen Receptor Splice Variant Enhances Estrogen-Stimulated Gene Expression. Mol Endocrinol 1998; 12: 1355-1366.

[33] Todorovic R, Ariese F, Devanesan P, et al. Determination of benz(a)pyrene - and 7,12-Dimethylbenz(a)anthracene DNA Adducts Formed in Rat Mammary Gland. Chem Res Toxicol 1997; 10: 941-947.

[34] Garner R. The role of DNA adducts in chemical carcinogenesis. Mutation Res 1998; 402: 67-75.

[35] Tamarkin L, Cohen M, Roselle D, Reicher C, Lippman M, Chabner B. Melatonin inhibition and pinealectomy enhancement of 7,12 dimethyl-benz(a)anthracene-induced mammary tumors in the rat. Cancer Res 1981; 41: 4432-4436.

[36] Subramanian A, Kothari LS. Suppressive effect by melatonin on different phases of 9,10-dimethyl-1,2-benzanthracene (DMBA)induced rat mammary gland carcinogenesis. Anti-Cancer Drugs 1991; 2: 297-303.

[37] Bartsch C, Bartsch H, Lippert TH, Gupta D. Effect of the mammary carcinogen 7,12-dimethylbenz(a)anthracene on pineal melatonin biosynthesis, secretion and peripheral metabolism. Neuroendocrinology 1990; 52: 538-544.

[38] Tamarkin L, Danforth DN, Lichter A, et al. Decreased nocturnal plama melatonin peak in patients with estrogen receptor positive breast cancer. Science 1982; 216: 1003-1005.

[39] Bartsch C, Bartsch H, Bellmann O, Lippert TH. Depression of serum melatonin in patients with primary breast cancer is not due to an increased peripheral metabolism. Cancer 1991; 67: 168-173.

[40] Wilson ST, Blask DE, Lemus-Wilson AM. Melatonin augments the sensitivity of MCF-7 human breast cancer cells to tamoxifen in vitro. J Clin Endocrinol Metab 1992; 75: 669-670. 